\title{
Cellular Based Automated Industrial CONTROL AND MONITORING SYSTEM
}

\author{
Farzana Sultana Dristy ${ }^{1}$ and Sadeque Reza Khan ${ }^{2}$ \\ ${ }^{1}$ Department of Computer Science and Engineering, Varendra Universty, Bangladesh \\ ${ }^{2}$ Department of Information and Communication Engineering, Chosun University, Korea
}

\begin{abstract}
Graphical User Interface (GUI) based systems are flourishing their popularity in the industrial area in present days. If it is possible to integrate the GUI based systems with a Global System for Mobile (GSM) modem for controlling and monitoring, it will be magnificently acceptable communication system. In this paper a method is presented on a distant machine and motor control system monitoring and controlling, using a GSM modem and GUI. PIC microcontroller is used to bridge and synchronize the operation of GUI and GSM systems.
\end{abstract}

\section{KEYWORDS}

GUI, GSM, PWM, SMS, AT Command.

\section{INTRODUCTION}

The starting of GUI based systems are exposed out from the conception of Human Computer Interaction in the early 60s [1].Now a days the use of GUI has achieved the position that makes our life easier by expecting some graphical windows. GUI's are very much reliable in the industrial control and monitoring [2]. The uses of GUIs are not only limited to industrial purposes but also available in general office communication purposes [3]. Advanced level GUI based system is also available for the purpose of monitoring water reactor properties [4].

In contrast with the mentioned systems, an updated control system is proposed here which is wireless and can maintain any industry using a modern GUI software. In this project a GSM modem is used to control machines on motor belt using Short Message Service (SMS). USB based communication is established with the PC or laptop to control machines as well as motor speed and its direction. Motor speed is also monitored through the USB. As a central controller PIC 18F2550 is used and advanced graphical compiler and simulator Flowcode is used. Visual Basic 2010 is the developer software for GUI.

\section{Proposed System}

PIC $18 \mathrm{~F} 2550$ is used in the proposed system as central controller. Two modes are used in the designed system, one is user interface (GUI) and another is wireless (GSM) which is shown in figure 1. Both modes are used to control the industrial machines as well as motor speed and rotating direction. The speed is also monitored through GUI and it is measured by using an autonics sensor (proximity sensor). 


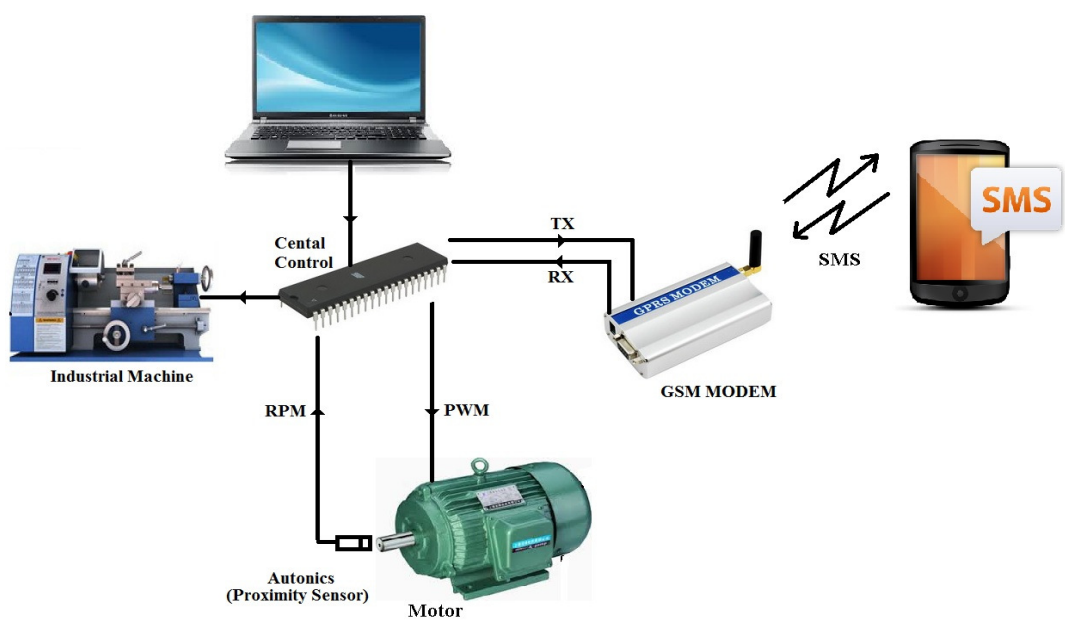

Fig:1: System overview

\section{USER INTERFACE DEVELOPMENT}

The Graphical User Interface (GUI) is designed with visual basic 2010 and showed in figure 2.

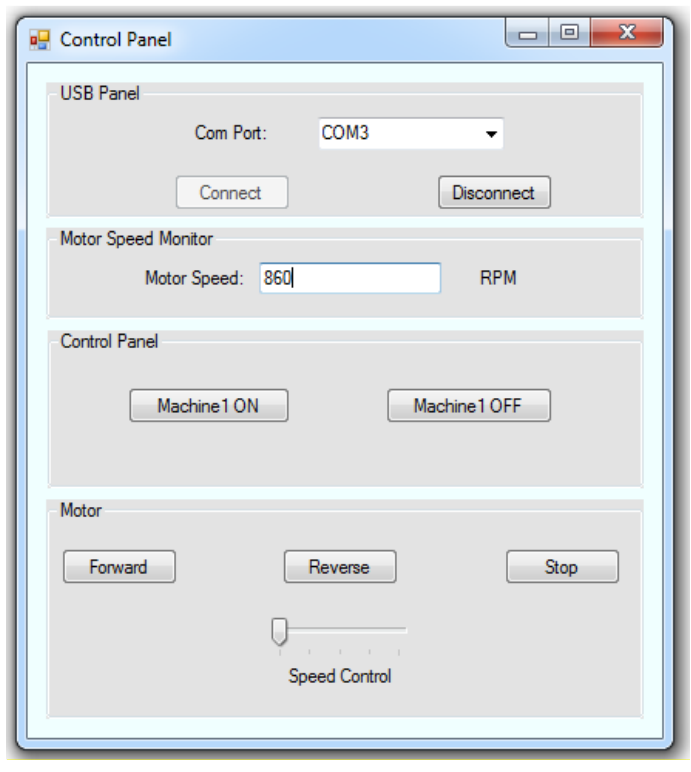

Fig:2: Designed GUI

Although other graphical software's (Java, C\#, Python, Perl etc) are available but visual basic is a drag and drop type software. Another reason to choose visual basic is its serial port integration property. The designed GUI for this project contains four sections. USB Panel section is used to select and connect the target Universal Serial Bus (USB) port. One section is dedicated for motor speed monitoring in rotation per minute (RPM) unit. Next section (Control Panel) is for industrial machine on and off. Although in this particular paper one machine is controller but any number of machines can be controlled through this section. Last is the Motor section is used to control the speed of the motor as well as the speed. 


\section{GSM INTERFACE}

For the purpose of wireless communication GSM (Global System of Mobile) modem SIM900 is used. The GSM modem operation is controlled by AT command. Basic AT command format is provided bellow:

Table 1: Basic AT command set

\begin{tabular}{|l|l|}
\hline \multicolumn{1}{|c|}{ Command } & \multicolumn{1}{c|}{ Description } \\
\hline AT & $\begin{array}{l}\text { Check if serial interface } \\
\text { and GSM modem is } \\
\text { working. }\end{array}$ \\
\hline AT \$AREG=0 & $\begin{array}{l}\text { AT command to turn off } \\
\text { the automated GSM } \\
\text { registration feature. }\end{array}$ \\
\hline AT+CFUN=1 & Turn the radio on. \\
\hline AT+COPS=0 & $\begin{array}{l}\text { Select network operator } \\
\text { for registration. }\end{array}$ \\
\hline AT+CGATT $=1$ & $\begin{array}{l}\text { AT command to start the } \\
\text { ATTACH sequence. }\end{array}$ \\
\hline ATD $<$ number $>$ & Dial to a number \\
\hline ATA & Answer \\
\hline AT+CMGF=1 & $\begin{array}{l}\text { Set message format to } \\
\text { TEXT mode. }\end{array}$ \\
\hline AT+CMGS="number" & $\begin{array}{l}\text { Send a message to the } \\
\text { telephone number. }\end{array}$ \\
\hline
\end{tabular}

General format of SMS is described below:

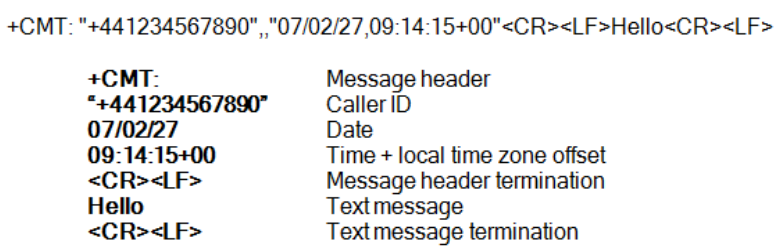

GSM modem is connected with the PIC microcontroller through level converter MAX232 [5, 6]. To control the machines and motor speed, rotation the received SMS through the central controller will be compared with the previously stored string set and generate the control signal.

\section{MOTOR SPEed CONTROL}

One simple and easy way to control the speed of a motor is to regulate the amount of voltage across its terminals and this can be achieved using "Pulse Width Modulation" or PWM. The pulse width modulation speed control works by driving the motor with a series of "ON-OFF" pulses and varying the duty cycle, the fraction of time that the output voltage is "ON" compared to when it is "OFF", of the pulses while keeping the frequency constant. 
Advanced Computational Intelligence: An International Journal (ACII), Vol.2, No.4, October 2015

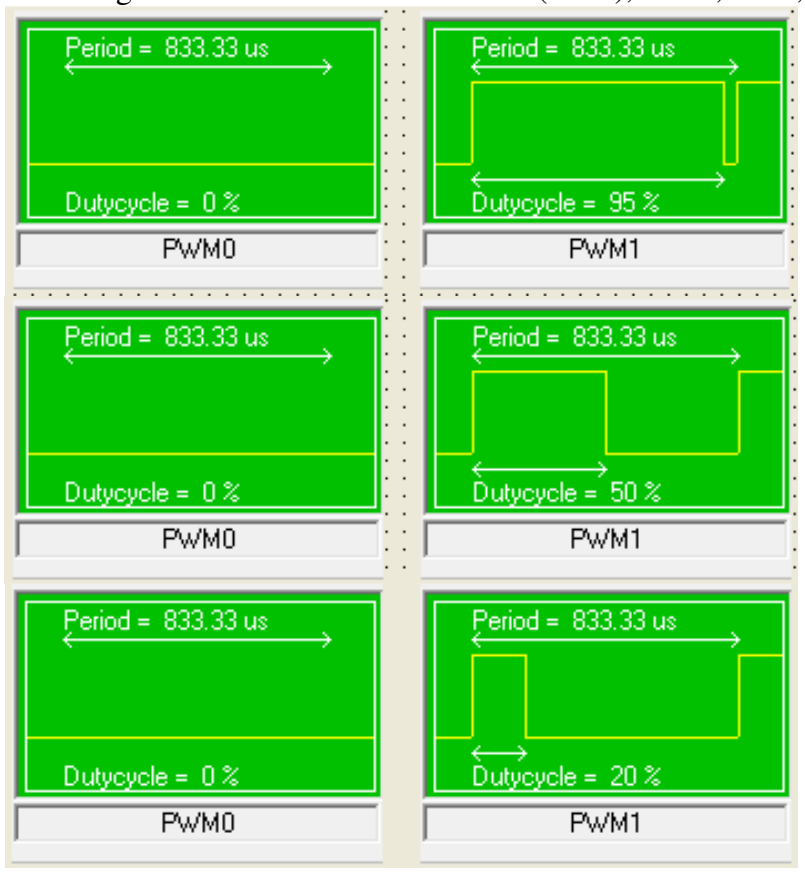

Fig:3: PWM for Clockwise Rotation at $20 \mathrm{MHz}$ Crystal
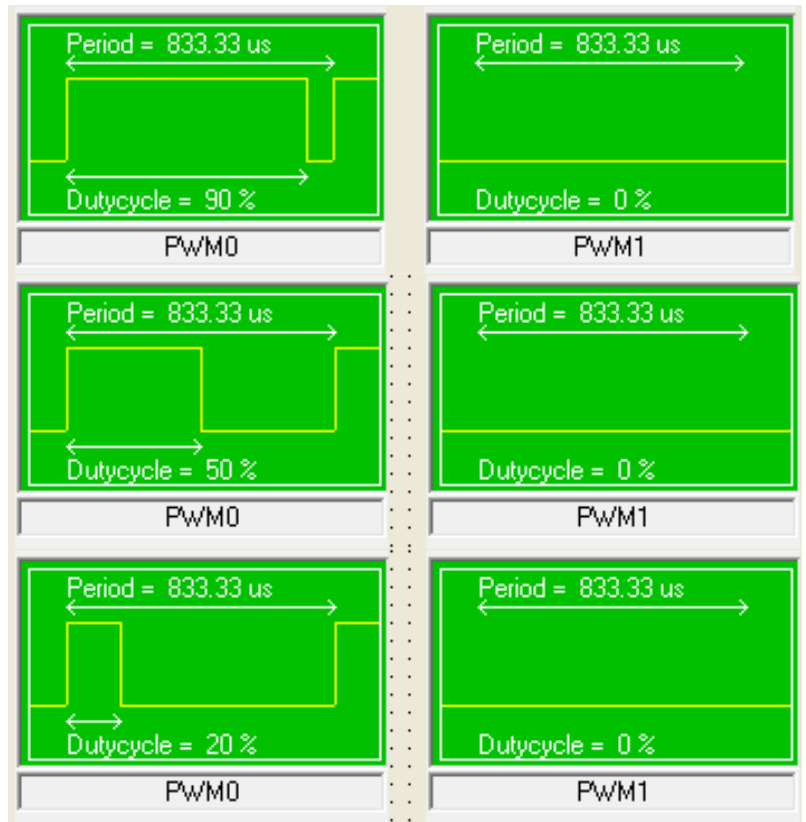

Fig:4: PWM for Anti-Clockwise Rotation at $20 \mathrm{MHz}$ Crystal

The power applied to the motor can be controlled by varying the width of these applied pulses and thereby varying the average DC voltage applied to the motors terminals. By changing or modulating the timing of these pulses the speed of the motor can be controlled, ie, the longer the pulse is "ON", the faster the motor will rotate and likewise, the shorter the pulse is "ON" the slower the motor will rotate. In other words, the wider the pulse width, the more average voltage 
Advanced Computational Intelligence: An International Journal (ACII), Vol.2, No.4, October 2015

applied to the motor terminals, the stronger the magnetic flux inside the armature windings and the faster the motor will rotate.

The rotational direction of the motor is controlled by L293D IC. Figure 3 and 4 are showing the clock and anti-clockwise rotation PWM signal simulation in Flowcode simulator for forward and reverse rotation of motor respectively.

\section{RESUlt AND DisCuSSION}

The PIC series 8 bit microcontroller PIC18F2550 is used as a central controller in this implemented system. The major purpose to select this microcontroller is its direct USB interface feature. Figure 5 shows the overall schematic diagram of the proposed system. The external interrupt (RB0) is used as motor speed measurement pin and a proximity sensor is connected to this pin which is used to count the number of revolution of the motor. RC0 pin is representing the output machine controlling. It can be accomplished by using an opto-coupler and a power relay. Any GPIO pin can be used for this purpose. The dedicated PWM pins (RC1 and RC2) are used to control the industrial motor. RC6 and RC7 are used for Universal Asynchronous Receiver Transmitter (UART) and GSM modem is controlled through those particular pins. MAX 232 IC is used as a level converter along with the GSM modem [5, 6].

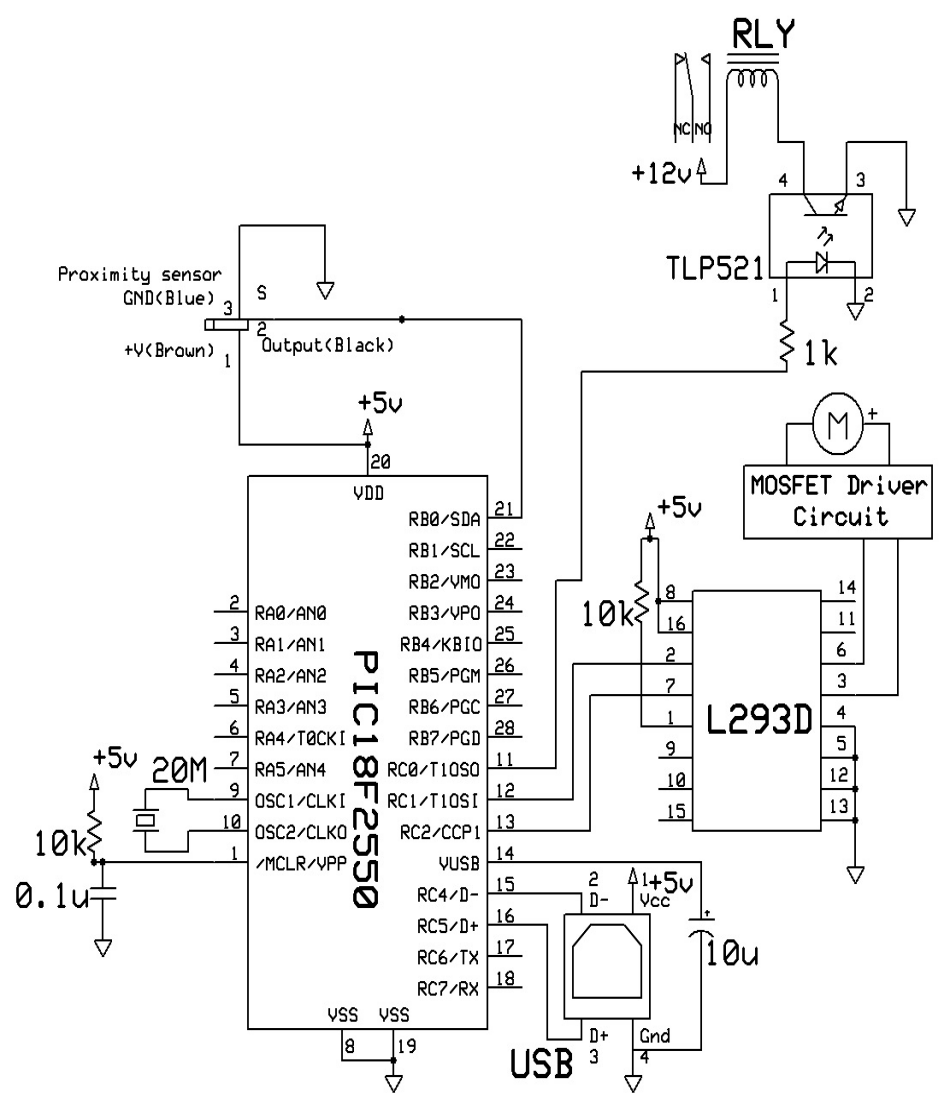

Fig: 5: Schematic Diagram of Implemented Circuit

Figure 6 shows the flowchart of the designed system. If the system is not connected with any COM port of the computer then the system will be controlled using the GSM network, else the system will be controlled by using the designed GUI. Figure 7 shows the implemented circuit 
Advanced Computational Intelligence: An International Journal (ACII), Vol.2, No.4, October 2015 which is tested in real time environment.

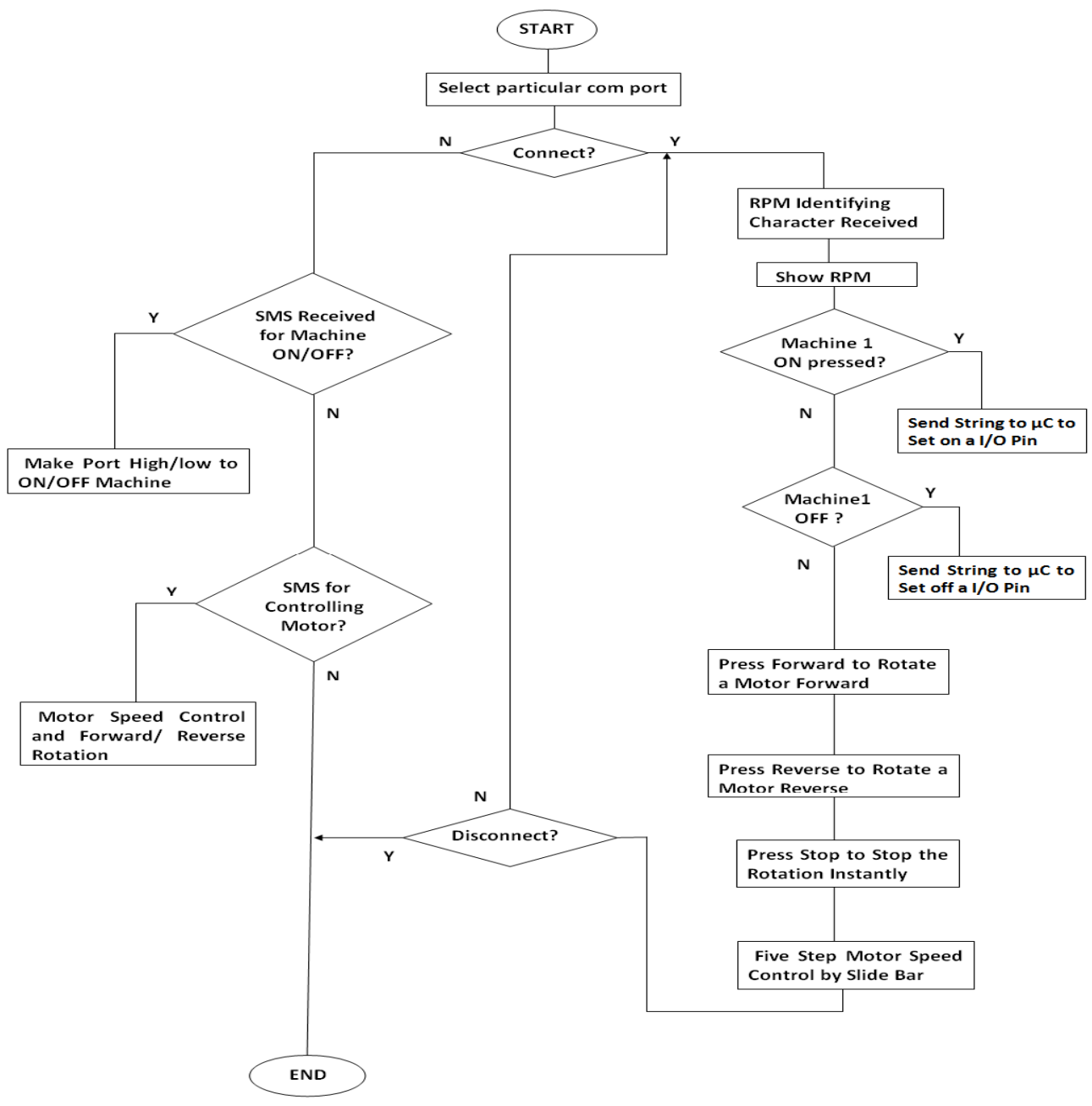

Fig: 6: Schematic Diagram of Implemented Circuit

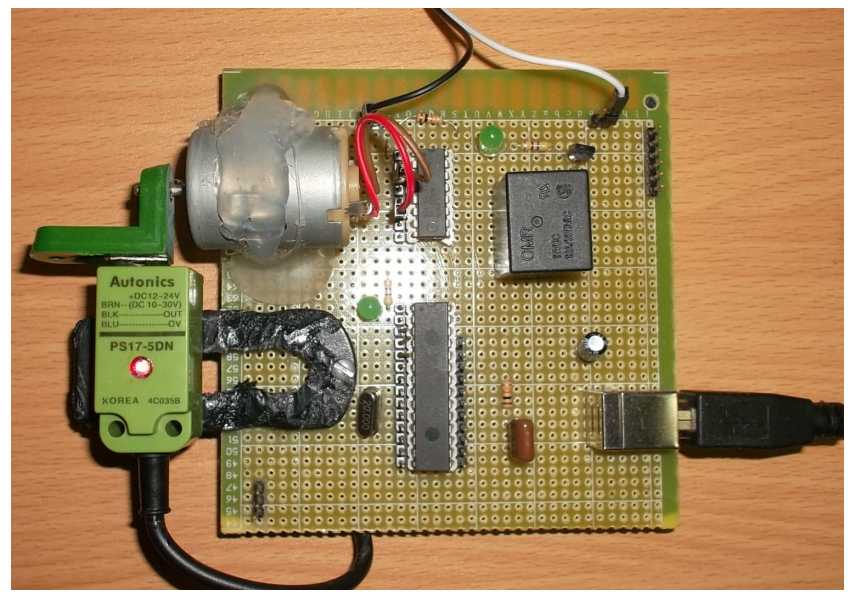

Fig: 7: Implemented and Tested Circuit 


\section{CONCLUSION}

Proposed system is a modern era setup for the controlling and monitoring of Industrial environment. Multiple machines can be controlled using the designed prototype. Motor torque monitoring in RPM unit and its speed controlling is a unique feature. Both the GUI and GSM controlling make the system more versatile and robust. This low cost system can be a promising device to fulfil the industrial monitoring and controlling setup.

\section{REFERENCES}

[1] Jorgensen, A. H. and Myers, B. A. "User interface history". Proceeding CHi '08 extended abstracts on Human factors in computing systems, 2008, pp. 2415-2418.

[2] Sadeque Reza Khan and Dr. M.S. Bhat, "GUI Based Industrial Monitoring and Control System", IEEE Power and Energy Systems Conference: Towards Sustainable Energy, 2014, pp: 1-4.

[3] Sadeque Reza Khan, Archis Banerjee, Dr. M. S. Bhat and Aritra Banerjee, "Wireless and GUI Based Smart Office Communication System", Digital Signal and Image Processing, Elsevier Science and Technology Publications, International Conference on Communication and Computing (ICC-2014), pp 44-51.

[4] Yu-Chen Chen, Yuan-Hsiang Chang, Te-Chuan Wang, "A Real Time Computer Graphical User Interface for Advanced Boiling Water Reactor Case Comparison Using MAAP Software", Computer Symposium (ICS), 2010 International IEEE conference, pp. 274 - 278.

[5] Archis Banerjee, Sadeque Reza Khan and Dr. M. S. Bhat, "Modern Home Automation System for Energy Conservation",Digital Signal and Image Processing, Elsevier Science and Technology Publications, International Conference on Communication and Computing (ICC-2014), pp 98-105.

[6] Sadeque Reza Khan, Archis Banerjee, Dr. M. S. Bhat and Aritra Banerjee, "Advanced GSM Based Harvesting and Cultivation System", Digital Signal and Image Processing, Elsevier Science and Technology Publications, International Conference on Communication and Computing (ICC-2014), pp 1-8.

\section{Authors}

\section{Farzana Sultana Dristy}

Farzana Sultana Dristy is currently continuing her B.Sc. degree in Computer Science and Engineering at Varendra University, Bangladesh. She is involved in the research fields of Embedded System Designing and Robotics.

\section{Sadeque Reza Khan}

Sadeque Reza Khan received B.Sc. degree in Electronics and Telecommunication Engineering from University of Liberal Arts Bangladesh and He complered his M.Tech in VLSI Design from National Institute of Technology Kernataka (NITK), India. Currently he is doing Ph.D at SoC Design laboratory, Chosun University, Korea. His research interest includes VLSI, Microelectronics, Control System Designing and

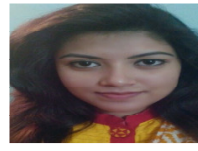
Embedded System Designing. 